\title{
JUURNAL.RU
}

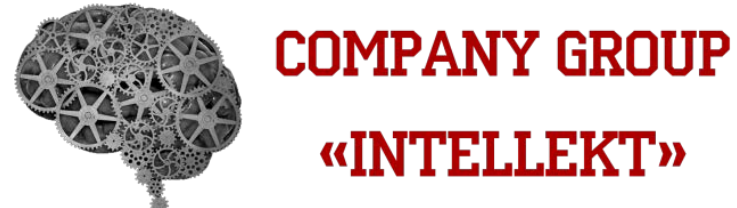

\author{
Турченко А.Е., Ильинская С.Ю. \\ Воронежский ГАСУ \\ Воронеж, Россия
}

doi: 10.18411/lj2016-5-5-05

\section{Исследование тенденций рынка отделочных материалов для пола}

Объем российского рынка отделочных материалов для пола по экспертным оценкам составляет от 48 до 52 миллиардов рублей, а годовой объем производства - 320 - 350 миллионов квадратных метров.

В структуре рынка напольных покрытий в 2013 году линолеум и напольная керамическая плитка заняли самые весомые доли - около 33 \% и 28,5 $\%$ соответственно, на третьем месте ламинат, на его долю приходится порядка 24 \%, на долю ковролина приходится $13 \%$, на долю паркета - 1,5 \% рынка в натуральном выражении. Объемы и динамика производства отделочных материалов для пола [1] представлены в таблице 1.

При этом, стоит отметить, что область применения данных изделий в соответствии с нормативной документацией отличается.

Так линолеум допускается применять в помещениях общественных и производственных зданий при отсутствии интенсивного движения и воздействия абразивных материалов, жиров, масел и воды [2].

Таблица 1

Объемы и динамика производства отделочных материалов для пола

\begin{tabular}{|c|c|c|c|}
\hline Вид отделочного материала & \multicolumn{3}{|c|}{ Объем выпуска млн м² в год } \\
\cline { 2 - 4 } для пола & $\mathbf{2 0 1 3}$ & $\mathbf{2 0 1 4}$ & $\mathbf{2 0 1 5}$ \\
\hline Линолеум & 124,6 & 131,2 & 141,9 \\
\hline Плитка керамическая & 73 & 86,1 & 92,5 \\
\hline Ламинат & 65,4 & 74,6 & 83,5 \\
\hline
\end{tabular}


Ламинат - предназначен для использования в помещениях, защищенных от воздействия влаги [3].

Керамическая плитка - предназначена для покрытия полов внутри помещений жилых и общественных зданий и в бытовых помещениях промышленных зданий, а также для покрытия полов в лоджиях и на балконах (неглазурованные плитки) [4]. Основные требования стандартов приведены в таблице 2

Таблища 2

Основные требования стандартов по физико-механическим показателям к отделочнылм материалам для пола

\begin{tabular}{|c|c|c|c|c|c|c|c|c|}
\hline \multirow{4}{*}{ Свойства } & \multicolumn{8}{|c|}{ Материалы отделочные для пола } \\
\hline & \multicolumn{2}{|c|}{ Керамическая плитка } & \multirow{2}{*}{\multicolumn{3}{|c|}{$\begin{array}{c}\text { Ламинат } \\
\text { Класс эксплуатации } \\
\end{array}$}} & \multicolumn{3}{|c|}{ Линолеум } \\
\hline & \multirow{2}{*}{$\begin{array}{l}\text { Не глазуро- } \\
\text { ванные }\end{array}$} & \multirow{2}{*}{$\begin{array}{c}\text { Глазуро- } \\
\text { ванные }\end{array}$} & & & & A & Б & B \\
\hline & & & 31 & 32 & 33 & \multicolumn{3}{|c|}{ от 1 до 1,5} \\
\hline $\begin{array}{c}\text { Водопогло-щение, } \\
\%, \\
\text { не более }\end{array}$ & 3,5 & 4,5 & 1 & $1-1,5$ & 1,5 & & & \\
\hline $\begin{array}{l}\text { Износостой-кость, } \\
\text { степень }\end{array}$ & - & $1-4$ & - & - & - & - & - & - \\
\hline Истираемость & \multicolumn{2}{|c|}{ 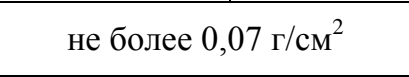 } & AC4 & AC6 & AC6 & $\begin{array}{c}50 \\
\text { MKM }\end{array}$ & $\begin{array}{c}90 \\
\text { МКM }\end{array}$ & $\begin{array}{l}100 \\
\text { МКM }\end{array}$ \\
\hline $\begin{array}{l}\text { Срок эксплуа- } \\
\text { тации, лет }\end{array}$ & \multicolumn{2}{|c|}{50} & $10-12$ & $12-15$ & $15-20$ & $7-20$ & $7-25$ & $10-30$ \\
\hline
\end{tabular}

Керамическая плитка имеет ряд ключевых преимуществ по сравнению с другими покрытиями: это прочность и легкость в уходе, она гигиенична и эко логична, огнеупорна, обладает анти статичностью, имеет длительный срок эксплуатации.

Несмотря на рост популярности таких относительно новых для российского рынка материалов, как ламинированный паркет, традиционные покрытия (линолеум и керамическая плитка) по-прежнему не оставляют рыночных позиций. Структура рынка напольных покрытий в России меняется под воздействием двух факторов: возникновение новых материалов, и стоимость строительных напольных материалов.

А вот будущее линолеума, по мнению специалистов, не выглядит стабильным. Линолеум открывает собой широкий спектр видов напольных покрытий, находясь на нижнем уровне «потребительской витрины». С ростом 
дохода интерес потенциального покупателя переходит от линолеума к более высоким по цене и качеству материалам: натуральному линолеуму (мармолеуму, который нередко относят к категории высококачественных линолеумов, хотя, по сути, это материал несколько другого рода), а также ламинату, ковролину, сборному и штучному паркету и т. п.

Таким образом, основным конкурентным преимуществом линолеума, несмотря на технологический прогресс современных производств, по-прежнему остается его ценовая доступность, то есть характеристика, постепенно утрачивающая свою актуальность, в то время как спрос на напольную керамическую плитку обусловлен еe незаменимыми качественными характеристиками.

В настоящее время на российском рынке напольных покрытий наметилась тенденция к вытеснению импортной продукции отечественной. Развитие производства вывело российские компании в лидеры в отдельных отраслях. В основном, это линолеум, продажей которого еще несколько лет назад занимались исключительно зарубежные компании. Сейчас присутствие российских изготовителей превышает 80 \% [5].

Основная тенденция рынка - продолжение вытеснения линолеума более новыми материалами - в первую очередь, ламинатом. Доля ламината достигла 20 \%, тогда как в 2003 г. - составляла не более 10 \% [6]. Это происходит по причине его невысокой стоимости и экономии средств при его монтаже. С учетом того, что стоимость ламината лишь немного выше традиционного для России линолеума, можно ожидать дальнейшее наращивание доли ламинированных покрытий.

Выполненное исследование основных потребительских свойств отделочных материалов для пола методом экспертных оценок [7], показало, что наиболее востребованными будут покрытия с длительным сроком службы, низкой истираемостью и наибольшими прочностными показателями. Результаты исследований представлены в таблице 3. 
Данным требованиям в большей мере удовлетворяет керамическая плитка, устойчиво занимающая на рынке напольных покрытий 2 место. Также можно отметить, что спрос не нее на рынке более устойчив, в сравнении с другими видами отделочных материалов для пола.

Таблица 3

Основные потребительские свойства отделочных материалов для пола оцененные

\begin{tabular}{|c|c|c|c|c|c|c|c|c|c|c|}
\hline \multirow{2}{*}{$\begin{array}{l}\text { Наименование } \\
\text { свойств }, i\end{array}$} & \multicolumn{6}{|c|}{$\begin{array}{c}\text { Значение } \\
\text { бальной } \\
\text { оценки М } \\
\text { по экспертам }\end{array}$} & \multirow{2}{*}{$\begin{array}{c}\text { Сумма } \\
\text { баллов по } \\
\text { каж-дому } \\
\text { свойству } \\
\sum_{i=1}^{n} M\end{array}$} & \multirow{2}{*}{$\begin{array}{c}\text { Средняя } \\
\text { сумма } \\
\text { баллов } \\
\text { одного } \\
\text { свойства } \\
r \times \sum_{g=1}^{r} M \\
\end{array}$} & \multirow{2}{*}{$\begin{array}{c}\text { Отклонени } \\
\text { е оценки } \\
\text { каждого } \\
\text { свойства от } \\
\text { сред-ней } \\
\text { сум-мы } \\
\text { бал-лов } S_{i}\end{array}$} & \multirow{2}{*}{$\begin{array}{c}\text { Квадрат } \\
\text { отклонений } \\
\text { от средней } \\
\text { суммы } \\
\text { баллов по } \\
\text { каждому } \\
\text { свойству } \\
S_{i}^{2}\end{array}$} \\
\hline & 1 & 2 & 3 & 4 & 5 & 6 & & & & \\
\hline $\begin{array}{c}\text { 1. Отклонения от } \\
\text { номинальных размеров }\end{array}$ & 1 & 1 & 1 & 1 & 1 & 1 & 6 & \multirow{6}{*}{18} & 12 & 144 \\
\hline $\begin{array}{c}\text { 2.Предел прочности при } \\
\text { изгибе }\end{array}$ & 4 & 3 & 4 & 2 & 4 & 5 & 22 & & -4 & 16 \\
\hline 3. Истираемость & 5 & 4 & 2 & 3 & 2 & 3 & 19 & & -1 & 1 \\
\hline 4. Вотопоглощение & 2 & 2 & 3 & 4 & 3 & 2 & 16 & & 2 & 4 \\
\hline 5. Срок службы & 3 & 5 & 5 & 5 & 5 & 4 & 27 & & -9 & 81 \\
\hline $\begin{array}{c}\text { Сумма баллов по каждому } \\
\text { эксперту, } \\
\sum_{g=1}^{r} M\end{array}$ & \multicolumn{7}{|c|}{15} & & & $\sum_{\substack{i \\
246}}^{a} S_{I}^{2}$ \\
\hline
\end{tabular}

методом экспертных оценок

$$
W=\frac{12 \times \sum_{i=1}^{n} S_{i}^{2}}{r^{2} \times\left(n^{3}-n\right)}=\frac{12 \times 246}{36 \times(120}=0.7
$$

где $\sum_{i}^{a} S_{I}^{2}$ - сумма квадратов отклонений і свойства от средней суммы баллов

r - количество экспертов;

n - количество свойств.

W - коэффициент конкордации, показывает существует ли неслучайная согласованность экспертов.

По оценке специалистов [6], в последнее время наблюдается изменение характера спроса на напольные покрытия. Цена как фактор, определяющий 
выбор, постепенно отходит на второй план. Критериями для оценки продукции покупателем становятся дизайн и безопасность.

\section{Литература:}

1. А.А. Семенов Перспективы развития строительного комплекса и промышленности строительных материалов в 2016 г.//Строительные материалы. 2015. №1. С. 4-6.

2. ГОСТ 32304-2013 Ламинированные напольные покрытия на основе древесноволокнистых плит сухого способа производства. Технические условия.

3. ГОСТ18108-80 Линолеум поливинилхлоридный на теплозвукоизолирующей подоснове.

4. ГОСТ 5787-2001 Плитки керамические для полов. Технические условия.

5. http://www.marketcenter.ru/content/doc-2-13177.html

6. http://parquetua.blogspot.ru/2015/03/blog-post_7.html

7. Акулова И.И. Организация и планирование маркетинга: методические. указания к практическим занятиям /И.И. Акулова; Воронеж. гос. архстроит. ун-т. - Воронеж, 2015. - 108 с. 